\title{
A RELAÇÃO ESCOLA-FAMÍLIA E A ORGANIZAÇÃO DO TRABALHO PEDAGÓGICO NA EDUCAÇÃO INFANTIL ${ }^{1}$
}

\author{
LA RELACIÓN ESCUELA-FAMILIA Y LA ORGANIZACIÓN DEL TRABAJO \\ PEDAGÓGICO EN LA EDUCACIÓN INFANTIL
}

\author{
THE SCHOOL-FAMILY RELATIONSHIP AND THE PEDAGOGICAL \\ WORK'S ORGANIZATION IN CHILDREN'S EDUCATION
}

\author{
Gilmara Lupion MORENO²
}

\begin{abstract}
RESUMO: A temática em questão justifica-se em razão da importância da relação professor-escola-família na educação da criança pequena e das constantes mudanças históricas, sociais, econômicas e culturais vivenciadas pelas duas instituições (escola e família) na atualidade. Desse modo, busca-se, num primeiro momento, dialogar com diferentes autores sobre a relevância da relação escola-família na educação infantil. Num segundo momento, com o intuito de colaborar com os gestores e professores dessa etapa da educação básica, o texto apresenta algumas possibilidades para o trabalho com as crianças sobre o tema família, e com as famílias no cotidiano das instituições de educação infantil. Espera-se com esse artigo dar visibilidade às diferentes formas para o trabalho com as famílias, e destacar a necessidade da escola manter seus conhecimentos atualizados sobre as crianças e suas famílias.
\end{abstract}

PALAVRAS-CHAVE: Escola. Família. Educação infantil.

RESUMEN: La temática en cuestión se justifica en razón de la importancia de la relación profesor-escuela-familia en la educación del niño pequeño y de los constantes cambios históricos, sociales, económicos y culturales vivenciados por las dos instituciones (escuela y familia) en la actualidad. De ese modo, se ha buscado en un primer momento, dialogar con diferentes autores a respecto de la relevancia de la relación escuela-familia en la educación infantil. En un segundo momento, con la intención de colaborar con los gestores y profesores de esa etapa de la educación básica, el texto presenta algunas posibilidades para el trabajo con los niños sobre el tema familia, y con las familias en el cotidiano de las instituciones de educación infantil. Se espera con ese artículo dar visibilidad a las diferentes formas para el trabajo con las familias, y salientar la necesidad de la escuela mantener sus conocimientos actualizados sobre los niños y sus familias.

PALABRAS CLAVE: Escuela. Familia. Educación infantil.

\footnotetext{
${ }^{1}$ Este texto é fruto da Tese de Doutorado “A relação professor-escola-família na educação da criança de 4 a 6 anos: estudo de caso em duas instituições de ensino da cidade de Londrina" apresentada ao Programa de PósGraduação em Educação da Faculdade de Educação da Universidade de São Paulo.

2 Universidade Estadual de Londrina (UEL), Londrina - PR - Brasil. Professora adjunta da Universidade Estadual de Londrina. Doutora em Educação. ORCID: 〈http://orcid.org/0000-0002-4435-878X>. E-mail: gilmaralupion@hotmail.com
} 
ABSTRACT: The present theme is justified by the importance of the teacher-school-family relationship in the young child's education and the historical, social, economic and cultural constant changes experienced by the two institutions (school and family) nowadays. Thus, it is sought, at first, dialogue with different authors about the relevance of the school-family relationship in early childhood education. In a second moment, in order to collaborate with the managers and teachers of this stage of basic education, the text presents some possibilities for working with children on the family theme, and with families in the daily life of early childhood education institutions. It is expected during this article, to give visibility to the different ways to work with families and to highlight the school's necessities to keep its knowledge up to date on children and their families.

KEYWORDS: School. Family. Childhood education.

\section{Introdução}

A relação escola-família é relevante para o desenvolvimento infantil, tanto no âmbito escolar como familiar, pois muda-se o contexto, mas a criança é a mesma. Um bom relacionamento entre os adultos (professores, pais ou responsáveis) e as crianças na educação infantil faz com que estas se sintam seguras, confiantes e felizes.

Entretanto, faz-se necessário refletir sobre o conceito de família. Isto é, de que família se está falando quando pensamos na organização do trabalho pedagógico na educação infantil. A família é uma instituição histórica e social que se transformou. Dessa forma, descarta-se a noção de que há um modelo de organização familiar, pois existe "uma diversidade de padrões familiares, pautados num projeto de relações interpessoais, não necessariamente referendados em laços sanguíneos" (SAMBRANO, 2006, p. 144).

Sabe-se que a família mudou e os papéis desempenhados por seus membros, entre eles: avós à moda antiga; avós 'modernos'; mãe chefe de família; homem/pai que cuida dos seus filhos - leva à escola, participa de reuniões, leva ao médico, ao dentista, ocupa-se do banho e da alimentação das crianças, coloca para dormir, ajuda os filhos(as) na lição de casa, etc. - tarefas estas vistas no passado como responsabilidade apenas da mulher/mãe.

Quando falamos de educação infantil é consensual que a família e a escola desempenham papéis importantes na educação da criança pequena. "Família e escola são dois temas avizinhados no debate sobre o trabalho educativo" (SAYÃO; AQUINO, 2006, p. 13). Sobre o impacto da escola na vida das famílias, os respectivos autores sinalizam vários fatores que interferem no cotidiano familiar, tais como o tempo, o espaço e o orçamento. Entretanto, há outros que interferem na convivência familiar, como por exemplo: a lição de casa e as atividades extracurriculares de final de semana. 
Segundo Sayão e Aquino (2006), a relação entre a família e a escola ocorre numa tensa zona de fronteira e, na maioria das vezes, é um diálogo de surdos. "Mesmo que à distância, mesmo que sem intenção direta, a escola se imiscui na vida familiar e institui um tipo específico de relação: uma relação de poder. Por sinal, uma relação de poder absolutamente desigual" (SAYÃO; AQUINO, 2006, p. 86). De acordo com os autores, esta desigualdade se explica por se tratar de uma relação entre culturas institucionais distintas: a escola é uma organização coletiva, e a família um foco dirigido a cada um de seus membros.

Para Nicolau (2000), a escola é um espaço privilegiado para a elaboração da vida humana, assim, é necessário que esta se paute em uma "pedagogia que considere, entre outros cuidados, o fato de os seres humanos não se formarem ou se educarem através de ‘inculcações’ de ideias, mas sim através da experiência coletiva de relações com a natureza e com outros seres humanos" (NICOLAU, 2000, p. 119). Já a família é a "primeira agência socializadora, é o lócus das primeiras relações e interações sociais e dos primeiros conhecimentos auferidos pelas crianças" (NICOLAU, 2000, p. 120).

Desse modo, a família e as escolas que se destinam às crianças pequenas são lugares privilegiados para a promoção do desenvolvimento das mesmas e, assim, estas duas instituições devem dialogar constantemente, de modo a estabelecer relações com o objetivo de buscar a superação de possíveis divergências.

De que criança e de que educação infantil se está falando? Como se relacionam as crianças, as famílias, os gestores e os professores no contexto escolar? Em busca destas respostas, este texto foi estruturado de modo a refletir sobre as crianças e os adultos (diretora, coordenadoras, professores, pais ou responsáveis) na instituição de educação infantil, pois, “[...] as interações que elas mantêm com as pessoas que lhe são próximas (familiares, professores, funcionários, colegas, amigos, vizinhos), [...] são fatores importantes aos processos de socialização, a tomada de consciência da realidade e seus valores" (NICOLAU, 2000, p. 119).

Sabe-se que "as concepções sobre crianças, suas culturas e modos de interação social se refletem na maneira como são encaradas e estruturadas as ações para com as crianças em diferentes contextos" (BARBOSA, 2009, p. 24). Pode-se dizer também que a forma como a criança é compreendida no contexto escolar reflete-se no modo como suas famílias são vistas e no tratamento dispensado a elas no cotidiano das instituições de educação infantil. 
No que diz respeito às crianças e suas famílias, como já foi dito, estas vivem suas infâncias em diferentes constituições familiares, logo, a escola e os professores devem respeitá-las com suas respectivas composições, com seus modos de expressar suas hipóteses, saberes e sentimentos, pois, com certeza, cada criança e cada família são iguais e diferentes. São iguais no que diz respeito aos seus direitos e diferentes no que se refere à especificidade de cada indivíduo, de cada grupo familiar. Nesse sentido, Nicolau ressalta que:

Aos professores cabe conhecer quais são as experiências das crianças fora da pré-escola, assim como a compreensão dos pais se enriquece quando tomam conhecimento de como é o dia de seus filhos junto aos educadores e às demais crianças. E nada mais espontâneo e natural do que conversar, relatar ocorrências e trocar ideias (NICOLAU, 2000, p. 121).

Quanto à relação entre a família e a instituição de educação infantil, as Diretrizes Curriculares Nacionais para a Educação Infantil (2009), no Art.7 ${ }^{\circ}$, inciso II, estabelecem que a proposta pedagógica das instituições de educação infantil deve cumprir a sua função sociopolítica e pedagógica, "assumindo a responsabilidade de compartilhar e complementar a educação e cuidado das crianças com as famílias" (BRASIL, 2009). O Art. 8, Parágrafo 1, Inciso III, propõe "a participação, o diálogo e a escuta cotidiana das famílias, o respeito e a valorização de suas formas de organização". Enfim, o documento em questão referenda o que diz a Constituição Federal (1988), o Estatuto da Criança e do Adolescente (1990), a Lei de Diretrizes e Bases da Educação Nacional (1996), e o Referencial Curricular Nacional para a Educação Infantil (1998) acerca da relação entre a família e a escola.

Com base no que estabelece a legislação sobre a relação e a parceria entre a família e a escola, respeitando-se o papel de cada uma das instituições, propõe-se as questões: Quais as facilidades e dificuldades encontradas entre ambas? Quais as expectativas das famílias e das escolas? Com o intuito de responder estas questões, buscouse na literatura a contribuição de diferentes autores acerca da relação e da parceria entre os professores, os familiares e os funcionários na educação pré-escolar.

Carvalho (2004), ao tratar das relações entre a escola e a família, afirma que as mesmas "baseiam-se na divisão do trabalho de educação de crianças e jovens envolvendo expectativas recíprocas" (CARVALHO, 2004, p. 41). No entanto, quando se trata da desejável parceria entre a escola e família e da participação dos pais na educação, de um modo geral, não são consideradas: 
[...] as mudanças históricas e a diversidade cultural nos modos de educação e reprodução social; as relações de poder entre estas instituições e seus agentes; a diversidade de arranjos familiares e as desvantagens materiais e culturais de grande parte das famílias; as relações de gênero que estruturam a divisão de trabalho em casa e na escola (CARVALHO, 2004, p. 41).

Além dos fatores apontados pela autora, acrescenta-se que, ao se analisar as relações entre as instituições - escola e família - não se pode desconsiderar o papel da mulher na sociedade contemporânea, independente de sua classe social, o que leva as famílias a buscarem as instituições de educação infantil para cuidado e educação de seus filhos. O avanço legal e teórico sobre a infância e a educação infantil tem propiciado a conscientização das famílias em relação ao direito da criança a essa etapa da educação básica.

Para Carvalho (2004), o currículo e a prática pedagógica "articulam os trabalhos educacionais realizados pela escola e pela família, segundo um modelo de família e papel parental ideal e com base nas divisões de sexo e gênero, subordinando a família à escola e sobrecarregando as mães, o que perpetua a iniquidade de gênero" (CARVALHO, 2004, p. 41). Contudo, observa-se que, nos dias atuais, esta situação tem sofrido algumas alterações, como, por exemplo, a maior participação dos pais nas atividades que envolvem as famílias na escola (reuniões, eventos, oficinas, etc.). As mães ainda são consideradas referência na comunicação entre a escola e as famílias, ou seja, quando necessário entrar em contato com a família, se telefona para elas, ou então, se envia um bilhete direcionado, exclusivamente, às mães.

No que diz respeito à educação da criança pré-escolar, convém que as instituições de ensino se ajustem às novas realidades, para não incorrerem em situações preconceituosas. Bassedas, Huguet e Solé (1999) citam pesquisas que alertam para o fato de que os professores não estão imunizados contra os preconceitos, tendendo a considerar mais problemáticas e inadaptáveis aquelas crianças oriundas de famílias não-padronizadas. Contudo, conforme as autoras, apesar dos resultados das pesquisas, "de qualquer forma, essas novas estruturas familiares sofrem de estresse [...], sobretudo em função dos estereótipos sociais construídos em torno de famílias diferentes que continuam vigentes" (BASSEDAS; HUGUET; SOLÉ, 1999, p. 284).

Ao tratarem da função dos professores em relação às famílias, os autores tecem algumas considerações, tais como o fato de que o desenvolvimento das crianças é um processo mediado social e culturalmente, que deve considerar a importância dos contextos 
(escola e família) em que esse crescimento pessoal se dá. Assim como a importância da relação entre os diversos microssistemas (escola e família) dos quais as crianças participam de fato, considerando-se que os contextos são diferentes, mas a criança é a mesma. Logo, o desencontro de opiniões existe, "na maneira como cada um dos contextos posiciona-se diante de uma perspectiva que não é idêntica a sua e que pode - ou não pode - aproximarse, posicionar-se a favor" (BASSEDAS; HUGUET; SOLÉ, 1999, p. 283).

Para superar as dificuldades vividas na relação entre escola e família, as instituições de educação infantil poderão compartilhar a ação educativa por meio de ações que permitam aos professores: conhecer a criança; estabelecer critérios educativos comuns; oferecer aos pais exemplos de intervenção e de relação com as crianças; e ajudá-los a conhecer a função educativa da escola, além de captar seus interesses, anseios, críticas e valores.

Para Bassedas, Huguet e Solé (1999), nas relações entre a instituição de educação infantil e as famílias, o conhecimento mútuo e o estabelecimento de acordos "atuam em benefício da criança pequena e promovem o seu bem-estar. As relações entre a família e a escola somente podem ser construtivas se estiverem baseadas no respeito mútuo, na confiança e na aceitação e das peculiaridades de cada um" (BASSEDAS; HUGUET; SOLÉ 1999, p. 296).

Ao se defender uma relação de 'trocas' entre a família e a escola, é importante que se considere, para o desenvolvimento de ambas, que para os pais e para os profissionais, tal relação:

[...] é um exercício de aceitação das diferenças. Os pais aprendem a exercer seu direito de participar do atendimento dado aos filhos, ao mesmo tempo em que aprendem a compreender o ponto de vista dos profissionais da educação infantil. Por outro lado, os profissionais aprendem seu direito de se fazerem ouvidos pelos pais, mas também aprendem seu dever de respeitar a cultura e o saber das famílias (MELLO, 2000, p. 25).

Spodek e Saracho (1998), ao abordarem as diferentes concepções de participação dos pais, o papel dos pais na educação na primeira infância, os diferentes níveis de participação parental, as técnicas para trabalhar com os pais e a educação para a primeira infância centrada na família, concluem que o trabalho com os pais é uma parte importante da educação. "Os professores precisam desenvolver um entendimento dos pais de seus alunos e da sua situação familiar, bem como uma variedade de técnicas para trabalhar com 
os pais de forma que sirvam de diferentes propósitos" (SPODEK; SARACHO, 1998, p. 184). Os autores destacam ainda que os professores devem "entender que a educação de crianças pequenas não pode ser considerada isoladamente. Para ter sucesso no trabalho com as crianças, os professores precisam da cooperação ativa dos pais" (SPODEK; SARACHO, 1998, p. 184).

Se a instituição de educação infantil não conceber as famílias como parceiras, poderá desencadear uma verdadeira luta para determinar qual das duas - a escola ou a família - está sendo mais competente na educação da criança. No entanto, é preciso compreender que "as duas instituições têm tarefas importantes, distintas e complementares, sendo a relação entre elas indispensável, complexa e desafiadora” (SAMBRANO, 2006, p. 139).

"A relação escola-família pode ser descrita como todas as formas de contato entre as escolas e as famílias (professores e pais) e vice-versa. [...] visando sempre ao bem-estar e ao sucesso escolar das crianças" (BHERING; SIRAJ-BLATCHFORD, 1999, p. 211). Entretanto, não há uma fórmula precisa que auxilie todas as escolas (e pais) e dê conta dos diferentes contextos, das diferentes necessidades de cada estrutura familiar e de cada criança, para colocar em prática o que propõe a teoria sobre as diversas maneiras de envolver os pais na instituição escolar. "O envolvimento de pais, devido ao seu caráter mutável [...], deve, entretanto, acompanhar as mudanças que ocorrem não só na sociedade em geral, como também as demandas das três partes envolvidas - escola, família e crianças” (BHERING; SIRAJ-BLATCHFORD, 1999, p. 212).

Especialmente na instituição de educação infantil, não é possível falar de criança e de trabalho pedagógico sem incluir a família. O trabalho com a criança pequena só será viável se houver uma estreita relação entre a escola e a família, relação esta que precisa ser pensada pelos profissionais da educação como uma função da escola, que, por sua vez, precisa ser planejada, realizada e avaliada continuamente, com o objetivo de garantir o desenvolvimento cognitivo e o bem estar físico, emocional, e social da criança.

Nicolau (2000) ressalta que "os papeis que a família e a pré-escola exercem são muito relevantes à criança no sentido de despertar-lhe o desejo de conhecer e participar da sociedade, entendendo a cultura como uma construção coletiva. Torna-se valioso o diálogo entre a família e o profissional da educação" (NICOLAU, 2000, p. 210). Para a autora, embora não seja fácil, mas um desafio, é possível construir uma relação de respeito e cumplicidade, entretanto, "se não houver parceria entre a pré-escola e as famílias [...], e se 
as naturais divergências e disputas não forem enfrentadas com naturalidade e com uma atitude dialógica, dificilmente os objetivos propostos serão atingidos de forma democrática e cooperativa" (NICOLAU, 2000, p. 120).

Para Silveira (2007), é urgente uma interação entre família e escola que promova a integração dos contextos de socialização das crianças, assim como a definição de papéis e funções educativas de forma clara. Entretanto, embora tanto uma como a outra procurem apoiar-se mutuamente, desencontram-se nesse interjogo das responsabilidades educativas. Pode-se inferir aqui que, como em qualquer relação, neste caso, entre a escola, os professores, os pais e as crianças, o desencontro de opiniões e as disputas são naturais e devem ser tratados com naturalidade, por meio do diálogo entre as duas instituições (escola e família).

Para concluir esta parte do texto destaca-se a experiência da educação para a primeira infância em Reggio Emilia, no que diz respeito à relação entre os professores, as crianças e suas famílias; Malaguzzi ${ }^{3}$ assinala a importância da presença dos pais na escola, para conversar com os professores, participar de uma reunião, ajudar a preparar excursões ou celebrações. "Tudo isso representa para as crianças exemplos de conduta que causa uma profunda impressão. Eles vêem um mundo onde as pessoas realmente ajudam umas às outras". (EDWARDS; GANDINI; FORMAN, 1999, p. 80).

Mas, como envolver os pais na organização do trabalho pedagógico na educação infantil? Para Spaggiari ${ }^{4}$, quando a discussão e a tomada de decisões são realizadas coletivamente, os pais encontram-se altamente envolvidos. Para os autores:

As ideias e habilidades que as famílias trazem à escola e, ainda mais importante, o intercâmbio de ideias entre pais e professores, favorecem o desenvolvimento de um novo modo de educar, e ajudam os professores a ver a participação das famílias não como uma ameaça, mas como um elemento intrínseco de companheirismo e como a integração de diferentes conhecimentos. (EDWARDS; GANDINI; FORMAN, 1999, p. 109-110).

Acredita-se que a experiência de Reggio Emilia, em especial no que diz respeito à relação entre professores, familiares e funcionários, na educação da criança, pode contribuir para a melhora da realidade das instituições de educação infantil brasileiras.

${ }^{3}$ Loris Malaguzzi, fundador e, por muitos anos, Diretor do Sistema de Reggio Emilia de Educação Municipal para a Primeira Infância.

4 No capítulo 4 do livro As Cem Linguagens da Criança, Sergio Spaggiari apresenta a estrutura organizacional do sistema municipal para a primeira infância e responde algumas questões elaboradas por Gandini. 
Por fim, conclui-se que para alcançar o objetivo de desenvolver uma educação infantil de qualidade, capaz de atender as necessidades das crianças neste nível de ensino, assim como mediar o seu processo de conhecer e descobrir o mundo a sua volta, é imprescindível uma relação saudável, de parceria, de cumplicidade, de compromisso entre a escola e as famílias na educação da criança pré-escolar.

Com o intuito de colaborar com os gestores e professores da educação infantil, a seguir serão apresentadas algumas possibilidades para o trabalho sobre o tema família com as crianças, e com as famílias no cotidiano das instituições de educação infantil.

\section{Família: conta pra gente como é a sua?}

$\mathrm{Na}$ qualidade de professor, o primeiro passo para trabalhar com as crianças o conteúdo 'família' é reconhecer, acolher e respeitar a diversidade familiar existente entre elas. Considerando as diferentes constituições familiares presentes nas escolas, e a recente conquista de direitos legais e sociais das famílias, como por exemplo, das homoparentais; o segundo passo, é que os familiares sejam comunicados que o conteúdo família será trabalhado com os pequenos, assim como suas diferentes composições.

Portanto, todos os tipos de família serão acolhidos e respeitados, esclarecendo que independente do sexo, do grau de parentesco, deverão ser consideradas pai e mãe as pessoas que exercem a função paterna e a função materna. Ou seja, a pessoa que tem vínculo com a criança, desenvolvido por meio da interação amorosa e contínua com a mesma, ou seja, o homem ou a mulher que dia após dia alimenta, banha, brinca, protege, estabelece limites, aprende amar a criança como filho(a). Tais orientações são direcionadas aos adultos (professores, pais ou responsáveis) nas instituições de educação infantil. Já para o trabalho sobre as 'famílias' com as crianças segue algumas propostas:

Roda de conversa - A roda é uma atividade diária na pré-escola, um momento de conversa. São muitas as possibilidades para trabalhar esta prática na educação infantil, as crianças e a professora podem levar para a roda suas novidades, dúvidas, sugestões, seus sentimentos. Ou então, organizar as atividades diárias. A roda deve ser formada sempre que necessário ou desejado, isto é, ela pode acontecer no início, no decorrer ou no término das atividades do grupo.

Portanto, a roda é uma possibilidade para conversar sobre as diferentes constituições familiares, bem como sobre o papel materno e o papel paterno, esclarecendo 
às crianças que esses nem sempre são realizados pelo papai e pela mamãe, pois existe avô, avó, tio, tia, irmão, irmã que cuidam, alimentam, brincam, dão afeto as crianças. Muitas são as perguntas que podem ser feitas nesse momento, tais como: O que é família? Quem são as pessoas da sua família? Quem mora com você? Quem cuida de você? O que é importante em uma família? Você conhece uma família diferente da sua?

Brincando de casinha - Uma das possibilidades para trabalhar família com os meninos e as meninas na pré-escola é a brincadeira, "o 'faz-de-conta' sociodramático das crianças, no qual as mesmas produzem, colaborativamente, atividades relacionadas a experiências de suas vidas reais, como, por exemplo, à cultura familiar" (CORSARO, 2002).

Nesse caso, é preciso organizar os espaços de forma a criar áreas para o brincar e selecionar os materiais e os brinquedos necessários para a brincadeira de faz-de-conta, nesse caso, a organização de cantos simbólicos, que sugerem a brincadeira de casinha. Estes cantos são um convite para que as crianças brinquem, de modo a reproduzir as rotinas familiares, podendo "experenciar significados que já ocorreram de alguma forma no seu cotidiano, como também construir algum significado que para ela é importante naquele momento de interação social” (MARTINS; SZYMANSKI, 2004, p. 179).

Acredita-se que o olhar atento do professor de educação infantil às ações das crianças nas brincadeiras de faz-de-conta, em especial naquelas que envolvem as funções de mãe, de pai, de filho, de irmão, de avô, de avó, etc., permite que o mesmo compreenda melhor a relação familiar em que a criança está envolvida e conheça um pouco mais sobre a constituição familiar das crianças. Com base nas constatações levantadas, o professor pode contribuir para a desconstrução de alguns estereótipos, como a atribuição exclusiva dos serviços domésticos à figura feminina, assim como a autoridade excessiva do pai em relação à mãe e aos filhos, entre outros.

Literatura infantil - Por entender que o faz-de-conta, o imaginário, a surpresa, a ludicidade presente nas histórias infantis costumam seduzir as crianças pequenas, e que ouvindo histórias elas podem sentir emoções importantes, destacamos a literatura infantil como uma das ricas possibilidades de discutir as relações familiares, e até mesmo as diversas composições familiares.

São diversos os títulos que tratam desta temática, contudo, ao selecionar o livro de literatura que tenha como foco as diferentes constituições familiares, é preciso que o professor considere a qualidade estética do texto, afinal trata-se de uma obra de arte 
literária. Importante também que o professor considere o conhecimento prévio dos alunos sobre o assunto, uma vez que, é da "coincidência entre o mundo representado no texto e o contexto do qual participa seu destinatário que emerge a relação entre a obra e o leitor" (ZILBERMAN, 1987, p. 23).

Confecção de um painel - Após conversar com as crianças sobre a existência de diferentes tipos de famílias, sobre o que realmente importa no dia-a-dia de cada uma delas, sugere-se a confecção de um painel com desenhos feitos pelas crianças das suas respectivas famílias. Se a opção for a fotografia, o professor deve solicitar a criança que leve para a escola sua foto preferida com a sua família, orientando-as que poderão estar na foto outras pessoas queridas, além do papai, da mamãe, do irmãozinho e da própria criança, descontruindo assim a ideia de 'família ideal' e construindo a de 'família real'. Acredita-se que esta proposta sintetiza o trabalho sobre o tema família com as crianças, uma vez que esta composição de imagens retrata as diferentes famílias existentes em cada grupo de crianças da educação infantil.

\section{Senhores pais e/ou responsáveis: trabalhando com as famílias na escola infantil}

Para uma relação saudável entre a família e a escola é essencial uma boa comunicação, afinal sabemos que o diálogo é a base em qualquer relação. Nesse caso, entendemos ser de suma importância que as escolas se organizem de modo que os horários de entrada e saída das crianças sejam também de diálogo dos professores com os familiares e/ou responsáveis das crianças. Quanto à comunicação escrita, orienta-se que a escola invista no envio de bilhetes, convites, convocações, etc. Entretanto, em razão da diversidade familiar, recomenda-se que o destinatário da correspondência enviada às famílias não se restrinja apenas à mãe ou ao pai, mas ao adulto responsável pela criança, algo simples, mas que demonstra o conhecimento e respeito da escola às diferentes constituições familiares.

Além de se utilizar dos instrumentos de comunicação tradicionais no âmbito administrativo da instituição de educação infantil, os professores devem deixar para trás o modo isolado e silencioso de trabalhar e "descobrir modos de comunicar e documentar as experiências crescentes das crianças na escola, devendo preparar um fluxo constante de informações de qualidade, voltado aos pais, mas também apreciado pelas crianças e pelos professores” (MALAGUZZI apud EDWARDS; GANDINI; FORMAN, 1999). 
Este fluxo de documentação contribui para que as famílias "reexaminem suas suposições sobre seus papéis como pais e suas visões sobre a experiência vivida por seus filhos e assumam uma abordagem nova e mais crítica com toda a experiência escolar" (EDWARDS; GANDINI; FORMAN, 1999, p. 80). Quanto às crianças, elas “[...] aprendem que seus pais sentem-se à vontade na escola, com os professores, e que estão informados sobre o que aconteceu e irá acontecer". (EDWARDS; GANDINI; FORMAN, 1999, p. 80).

São muitas as possibilidades de se comunicar as experiências das crianças na instituição de educação infantil, como por exemplo, a confecção de um banner por ocasião do término de um trabalho; a exposição dos trabalhos das crianças; a exposição de fotos, etc. Por fim, temos hoje os sites e as redes sociais como instrumentos de comunicação entre a escola e as famílias, entretanto, recomenda-se o devido cuidado com o uso de imagens dos pequenos, devendo estas estar previamente autorizadas pelos pais e/ou responsáveis, evitando assim constrangimentos de ambas as partes.

O primeiro passo para o trabalho com as famílias é reconhecer a importância destas na educação da criança pré-escolar, assegurando-lhe seus direitos, como por exemplo, o de conhecer a proposta pedagógica, de acompanhar o desenvolvimento do seu/sua filho(a). São muitas as oportunidades de interação da escola com as famílias, como as sugeridas pelos educadores italianos; os encontros por grupos; as pequenas reuniões em grupo; as conversas individuais; as reuniões sobre um tema; os encontros com um especialista; as sessões de trabalho; os laboratórios; as celebrações, entre outras (EDWARDS; GANDIN; FORMAN, 1999).

Entretanto, é preciso que os gestores e professores da educação infantil busquem estratégias para investir nas relações com os pais ou responsáveis por meio de ações que garantam uma participação de qualidade, concedendo-lhes o direito à voz; que possibilitem a inserção das famílias nos diferentes espaços e atividades da pré-escola (VASQUES et al, 2015). Sendo assim, segue algumas propostas para o trabalho com as 'famílias' na educação infantil, contudo, sabe-se que as estratégias apresentadas não são inéditas, muitas já são realizadas pelas escolas; entretanto, é preciso que a escola (direção, coordenação e professores) se sensibilize e passe a ter um novo olhar para os momentos junto às famílias.

Reuniões - Garantir a frequência dos pais nas reuniões convocadas pela escola costuma ser um desafio para os gestores e professores da educação infantil. O desafio aqui está em dar voz aos pais e responsáveis, ouvindo atentamente suas sugestões, opiniões e 
propostas, e sempre que possível acatando-as em prol de uma educação infantil de qualidade.

Entretanto, segue algumas sugestões para que as reuniões sejam bem sucedidas: o primeiro passo consiste em planejar o encontro, elaborando o roteiro da reunião. $\mathrm{O}$ segundo, em definir a data da reunião e enviar os convites, não é uma tarefa fácil encontrar uma data e um horário que atenda a maioria das famílias, contudo, "a agenda deve ser consensual e os pais devem ser notificados com bastante antecedência" (EDWARDS; GANDINI; FORMAN, 1999, p. 110). Os convites devem ser claros, com dia, local, hora para começar e terminar, e os temas a serem tratado na reunião.

Para receber as famílias sugere-se também a organização do ambiente, de modo que os pais ou responsáveis se sintam esperados e acolhidos. As famílias também apreciam bastante a exibição de vídeos que mostrem um pouco do cotidiano das crianças e do trabalho pedagógico da escola. Tal proposta contribui para o "envolvimento dos pais na aprendizagem dos filhos, oferece uma rica base para a discussão entre eles e aprofunda o entendimento que o adulto tem sobre a natureza da aprendizagem nos primeiros anos" (KATZ, 1999, p. 53).

Para garantir o sucesso da reunião, a direção, a coordenação e os professores devem reservar um tempo para que os pais possam fazer suas perguntas e propostas. Por fim, as crianças também podem contribuir para a realização da reunião, ajudando na organização do ambiente ou preparando um bolo, um biscoito, um suco, a ser servido às famílias no início ou no final da reunião.

Palestras e Oficinas - As palestras e oficinas também costumam fazer parte das atividades propostas pela escola; estas podem ser bastante úteis, quando da necessidade de se conhecer e discutir sobre uma temática, por isso, a fala de um especialista (pedagogo, médico, psicólogo, nutricionista, psicopedagogo, fonoaudiólogo, etc.) pode contribuir para ampliar os conhecimentos, ou mesmo esclarecer pais e professores sobre uma temática em questão. Para além dos aspectos teóricos, as oficinas podem auxiliar os familiares a compreender melhor um determinado assunto, por meio de atividades práticas, como por exemplo, a discussão em pequenos grupos do tema proposto. Ou ainda, a oferta de oficinas de caráter prático, como por exemplo, a preparação de lanches, a confecção de brinquedos, de livros de pano, etc.

Participação dos pais em projetos - A participação dos pais em trabalhos e projetos que envolvam as crianças é sempre muito bem vinda. São muitas as possibilidades 
de inserir as famílias nessas atividades, como por exemplo, convidando-os a colaborar na organização dos espaços, na confecção de um tapete para a hora do conto, de um suporte para livros, etc. (VASQUEZ et al, 2015). Ou então, programar a visita de uma pessoa da família que possa conversar com as crianças sobre sua profissão, contar uma história, fazer uma aula de culinária, um artesanato, etc.

Livro da vida - Inspirados na Pedagogia de Freinet, uma das escolas participantes da pesquisa que originou este texto trabalha com o Livro da Vida, que traz o registro das atividades da turma por meio da escrita e de desenhos das crianças, pequenos textos explicativos das propostas realizadas pelo grupo, redigidos pelas professoras, e fotos dos momentos mais significativos. O Livro da Vida é levado pelas crianças para o conhecimento e apreciação das famílias. Para as crianças, levar o livro da vida para casa é motivo de alegria, pois, com muito entusiasmo, no portão da escola, vão logo anunciando a seus familiares o têm que em mãos. As famílias também apreciam bastante a oportunidade de conhecer um pouco mais do trabalho realizado pelo grupo na escola.

Piquenique, recreação e atividades culturais - Dentre as atividades observadas em uma das escolas pesquisadas, destaca-se um evento promovido semestralmente pela escola, e bastante esperado e apreciado pelas famílias. O evento acontece em um sábado à tarde, ao ar livre, e objetiva reunir as famílias para se conhecerem melhor. Cada família leva um prato com doce ou salgado e uma bebida (refrigerante ou suco), compondo, assim, uma mesa farta.

Uma oportunidade para que pais e filhos brinquem juntos, pois são oferecidas diferentes propostas para que adultos e crianças possam pintar, desenhar, escalar, se movimentar. O evento conta ainda com uma apresentação cultural, isto é, uma apresentação musical, uma contação de história, a apresentação de um grupo de dança, etc. Enfim, uma tarde muito agradável, toalhas espalhadas pelo chão, adultos e crianças desfrutando da companhia uns dos outros, da luz do sol, da simplicidade e riqueza de um piquenique.

Entrega dos relatórios e portfólios - A avaliação na educação infantil serve "para o professor (re) planejar as atividades, preocupando-se em incluir todas as crianças e famílias nas metas que pretende atingir" (NICOLAU, 2009, p. 93), sendo este um aspecto importante na interação família-escola. Logo, uma oportunidade de troca, de informação, de aprendizagem entre os adultos na educação infantil. Os instrumentos de avaliação das 
crianças não necessariamente precisam ser entregues às famílias em uma reunião, pode-se planejar a entrega destes num final de tarde, no pátio, no quintal da escola.

A entrega dos relatórios, das pastas, dos portfólios é sempre um momento de realização, de comemoração, tanto para os professores, que se esmeram em organizá-los, quanto para as famílias, que podem, por meio destes, se aproximarem e conhecerem um pouco mais do cotidiano do seu/sua filho na instituição de educação infantil.

\section{Considerações finais}

Trabalhar o tema família com os profissionais da educação (direção, coordenação, professores e funcionários) nem sempre é algo que acontece de forma tranquila. É comum que esta discussão, ou seja, a família e sua relação com o trabalho realizado na escola transcorra em meio a acusações e preconceitos, pois, geralmente, a instituição responsabiliza as famílias quando algo não vai bem com a criança. Entretanto, as escolas devem fazer uma autocrítica de sua ação pedagógica e considerar os diferentes fatores que influenciam diretamente a vida de seus alunos no contexto escolar, desmistificando a ideia de que, na família, a criança está imune a situações de risco, e auxiliando as famílias a compreender a importância de ambas, escola-família, na vida da criança.

Por fim, destaca-se, a importância da disponibilidade da direção, coordenação e professores para manter seus conhecimentos atualizados sobre as crianças e para valorizar o papel dos pais na educação da criança. Além disso, é fundamental, para garantir a participação dos pais na escola, que os professores tenham habilidade para falar, ouvir e aprender com os mesmos, desfazendo muitas vezes, da ideia errônea de que os seus conhecimentos profissionais sobrepõem-se aos da família. Desse modo, espera-se que, juntos, escola e família possam unir esforços em defesa de uma educação que respeite o direito da criança a viver dignamente sua infância, gozando o que lhe é de direito: a convivência familiar e a educação infantil.

\section{REFERÊNCIAS}

BARBOSA, S. O que você esta escrevendo? na pesquisa com criança o exercício de compreender e ser compreendido. In: KRAMER, S. Retrato de um desafio: crianças e adultos na educação infantil. São Paulo: Ática, 2009. 
BASSEDAS, E.; HUGUET, T.; SOLÉ, I. Família e escola. In: BASSEDAS, E.; HUGUET, T.; SOLÉ, I. Aprender e ensinar na educação infantil. Porto Alegre: Artes Médicas Sul, 1999. p. 281-301.

BHERING, E.; SIRAJ-BLATCHFORD, I. A relação escola-pais: um modelo de trocas e colaboração. Cadernos de Pesquisa, Campinas, n. 106, mar,. 1999.

\section{BRASIL. Constituição (1988). Constituição da República Federativa do Brasil.}

Disponível em: <http://www.planalto.gov.br/ccivil_03/Constituicao/Constituicao.htm>. Acesso em: 01 set. 2016.

BRASIL. Lei n. 8.069, de 13 de julho de 1990. Dispõe sobre o Estatuto da Criança e do Adolescente e dá outras providências. Disponível em: <http://www.planalto.gov.br/ ccivil_03/leis/18069.htm>. Acesso em: 15 ago. 2012.

BRASIL. Lei n. 9.394, de 20 de dezembro de 1996. Estabelece as diretrizes e bases da educação nacional. Disponível em:

<http://www.planalto.gov.br/ccivil_03/LEIS/19394.htm>. Acesso em: 15 ago. 2012.

BRASIL. Ministério da Educação e do Desporto. Secretaria de Educação Fundamental. Referencial curricular nacional para a educação infantil. Brasília, 1998. Disponível em: 〈http://portal.mec.gov.br/seb/arquivos/pdf/rcnei_vol1.pdf〉. Acesso em: 15 ago. 2012.

BRASIL. Ministério da Educação. Conselho Nacional de Educação. Câmara de Educação Básica. Resolução n. 5, de 17 de dezembro de 2009. Fixa as Diretrizes Curriculares Nacionais para a Educação Infantil. Disponível em:

$<$ http://portal.mec.gov.br/index.php?option=com_docman\&view=download\&alias=2298rceb005-09\&category_slug=dezembro-2009-pdf\&Itemid=30192>. Acesso em: 27 mar. 2017.

CARVALHO, M. E. P. de. Modos de educação, gênero e relações escola-família. Cadernos de Pesquisa, Campinas, v. 34, n. 121, jan./abr., 2004.

CORSARO, William A. A reprodução interpretativa do brincar ao "faz-de-conta" das crianças. Educação, Sociedade \& Cultura, n.17, 2002, p.113-134.

EDWARDS, C.; GANDINI, L.; FORMAN, G. As cem linguagens da criança: a abordagem de Reggio Emilia na educação da primeira infância. Porto Alegre: Artes Médicas Sul, 1999.

MARTINS, E.; SZYMANSKI, H. Brincando de casinha: significado de família para crianças institucionalizadas. Estudos de Psicologia, Natal, v. 9, n. 1, p. 177-187, 2004.

MELLO, A. M. Um diálogo com os diretores de creches e pré-escolas. In: ROSSETTIFERREIRA, M. C. et al. Os fazeres na educação infantil. 2 ed. São Paulo: Cortez, 2000. 
NICOLAU, M. L. M. Avaliação escolar. In: CLEBSCH, J. Educação 2009: as mais importantes tendências na visão dos mais importantes educadores. Curitiba: Multiverso, 2009.

NICOLAU, M. L. M. Escolarização e socialização na educação infantil. Acta Scientiarum, Maringá, v. 22, n. 1, p. 119-125, 2000.

SAMBRANO, T. M. Relação instituição de educação infantil e família: um sonho acalentado, um vínculo necessário. In: ANGOTTI, M. (Org.). Educação Infantil: para quê, para quem e por quê? Campinas: Editora Alínea, 2006.

SAYÃO, R.; AQUINO, J. G. Família: modos de usar. Campinas: Papirus, 2006.

SILVEIRA, L. M. O. B. A interação família-escola frente aos problemas de comportamento da criança: uma parceria possível? 2007. 109 f. Tese (Doutorado em Psicologia) - Pontifícia Universidade Católica do Rio Grande do Sul, Porto Alegre, 2007.

SPODEK, B.; SARACHO, O. N. Trabalhando com os pais. In: SPODEK, B.; SARACHO, O. N. Ensinando crianças de três a oito anos. Porto Alegre: Artmed, 1998.

VASQUES et al. O envolvimento das famílias: uma trajetória de descobertas e conquistas compartilhadas. In: KISHIMOTO, T. M. (Org). Narrativas das professoras em contexto colaborativo. São Paulo: Pontão de Cultura/Ministério da Cultura/FEUSP, 2015.

ZILBERMAN, R. A criança, o livro e a escola. In: ZILBERMAN, R. A literatura infantil na escola. 6. ed. São Paulo: Global Ed., 1987. p. 11-32.

\section{Como referenciar este artigo}

MORENO, Gilmara Lupion. A relação escola-família e a organização do trabalho pedagógico na educação infantil. Revista Ibero-Americana de Estudos em Educação, Araraquara, v. 13, n. 03, p. 1187-1203, 2018. E-ISSN:1982-5587. DOI: 10.21723/riaee.v13.n3.2018.9778

Submetido em: 27/04/2017

Revisões requeridas: $12 / 06 / 2017$

Aprovado em: 03/08/2017 